\title{
Aortodigestive Fistula: A Rare Cause of Digestive Bleeding
}

\author{
Nada Lahmidani*, Mouna Figuigui, Hakima Abid, Mounia El Yousfi, Mohammed El Abkari, \\ Sidi Adil Ibrahimi, Dafr Allah Benajah
}

Department of Gastroenterology, University Hospital Hassan II, Sidi Mohammed Ben Abdallah University, Fez, Morocco

Email: *nadalahmidani1982@gmail.com

How to cite this paper: Lahmidani, N., Figuigui, M., Abid, H., El Yousfi, M., El Abkari, M., Ibrahimi, S.A. and Benajah D.A. (2021) Aortodigestive Fistula: A Rare Cause of Digestive Bleeding. Case Reports in Clinical Medicine, 10, 126-132. https://doi.org/10.4236/crcm.2021.104015

Received: February 24, 2021

Accepted: April 22, 2021

Published: April 25, 2021

Copyright $\odot 2021$ by author(s) and Scientific Research Publishing Inc. This work is licensed under the Creative Commons Attribution International License (CC BY 4.0).

http://creativecommons.org/licenses/by/4.0/

(c) (i) Open Access

\begin{abstract}
Backgound: Aorto-digestive fistulas remain a fatal disease entity often occurring after vascular surgeries. Eso-gastro-duodenal endoscopy is essential to explore the upper digestive bleeding. The negativity of morphological examinations should not exclude the diagnosis. Diagnosis has benefited in recent years from developments in cross-sectional imaging: computed tomography (CT) and magnetic resonance imaging (MRI). The severity of bleeding is linked to the vital consequences (mortality close to $50 \%$ up to $100 \%$ in the absence of treatment), functional (30\% amputation), and to the underlying infection itself correlated with the attack of the stent and the anastomosis. Patients: We report three cases of aorto-digestive fistulas treated at The University Hospital Hassan II to show the challenging diagnosis and therapeutic of such rare causes of upper digestive bleeding. Results: three patients were admitted to the emergency endoscopy unit for upper digestive bleeding, 2 of them had a medical history of Behcet Disease and two had past aortic aneurism surgery. The couple's upper endoscopy and CT scan angiography made the diagnosis. Unfortunately, 2 patients died from fatal bleeding. Conclusion: Aortodigestive fistula is an extremely serious complication of aortic aneurisms and a rare cause of gastrointestinal bleeding. This diagnosis should be considered in any patient presenting with digestive bleeding with vascular disease or previous history of vascular stent.
\end{abstract}

\section{Keywords}

Aorto Digestive, Fistula, Bleeding, Endoscopy, Primary

\section{Introduction}

The aero digestive fistulas are direct communications between the abdominal aorta and the digestive tract. They generally occur in the continuations of a vas- 
cular surgery [1]. Primary aero digestive fistulas spontaneously developing are rare [1]. They often complicate a vascular surgery (80\%) [1] [2]. The fistulisation can happen on the level of any digestive segment from the esophagus to the colon, but the most frequent site is the duodenum (83\%) particularly in its third portion [1] [2]. It is explained by the fixity of the distal part of the duodenum and its proximity to the aorta. The onset of aero digestive fistula follows the expansion of the aortic aneurysm which causes irritation and inflammation of the duodenal wall resulting in interdigestive fistulization over time [3] [4].

We reviewed the medical files of three patients admitted for digestive bleeding on aorto digestive fistulas at the emergency department of gastroenterology at the University Hospital Hassan II Fez Morocco. We illustrate in these observations the challenges in the diagnosis and management of this rare cause of digestive bleeding.

\section{Patients}

\subsection{Observation 1}

Mr. K.A., a 45 years old patient, with a medical history of Behçet disease since 1995 under colchicine. The patient presented at the emergency department with abdominal pain, melena of great abundance. At admission, blood pressure was low $(90 / 50 \mathrm{~mm} \mathrm{Hg})$, rose to $110 / 65 \mathrm{~mm} \mathrm{Hg}$ after infusion of 1 liter of normal saline, heart rate was 100 per minute. Abdominal examination objectified a beating umbilical mass. Hemoglobin was $70 \mathrm{~g} / \mathrm{l}$. Upper gastrointestinal endoscopy was immediately performed. No blood or any lesion was found in the upper digestive tract. Colonoscopy also showed melena without any suspicious lesion. A computed angiography scan showed a sacciform aneurism of the abdominal aorta under renal artery, partially thrombosed with hemorrhagic transformation within the thrombus, the patient was admitted to the operating room where he benefited from a flattening of his aneurysm with bi-liac aorto bypass, then the patient was transferred to the internal medicine department for initiation of immunosuppressive treatment, the evolution was marked by the release of the proximal and distal anastomosis of the aorto-aortic bypass. The patient was then hospitalized in the intensive care unit, unfortunately, he developed a massive bleeding shock and died 2 days after that.

\subsection{Observation 2}

Mr. B.M., a 52 years old patient, with a medical history of angiobehçet under cyclophosphamide. He underwent 5 years ago surgery for aneurism of the abdominal aorta with a bridging aorto $\mathrm{Bi}$ iliac also followed for venous thrombosis under acenocoumarol for 1 year. He was admitted to the emergency department for upper gastrointestinal bleeding. Hemoglobin was $9 \mathrm{~g} / \mathrm{dl}$, platelet count 315,000 , NIR at 3.5. Upper digestive endoscopy showed a large blood clot at the third duodenum measuring approximately $20 \mathrm{~mm}$ with the probable migration of the aortic stent in the duodenum, Figure 1. An angio abdominal computed 
tomography scan confirmed the stent migration with the aorto duodenal fistula, Figure 2. The hemodynamic state of the patient went unstable unconscious, $\mathrm{He}$ was soon admitted for emergent surgery but unfortunately died in the operating room.

\subsection{Observation 3}

Mr. B.L., a 65 years old patient, with aorto bi-iliac bridging in $2017 \mathrm{f}$ at the United States. Admitted 5 months ago at the emergency department for upper GI bleeding of great abundance with hemodynamic instability preceded by abdominal pain. At admission, he had low blood pressure 90/60 $\mathrm{mmHg}$, hemoglobin at $8.3 \mathrm{~g} / \mathrm{dl}$. Upper digestive endoscopy, objectified fresh blood beyond the second duodenum with no lesion. The abdominal CT angiogram showed the presence of a left later aortic collection with hydroaeric content and containing spontaneously hypodense areas. After 96 hours of monitoring without recurrence of bleeding, the patient returned to her home, is awaiting her programming for a prosthesis.

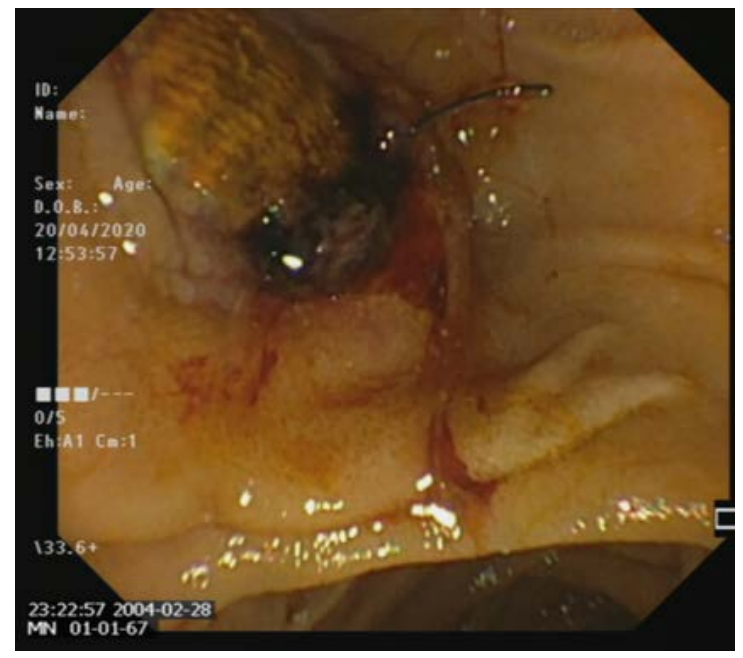

Figure 1. Blood clot at the duodenuma with erosion of the wall by the stent.

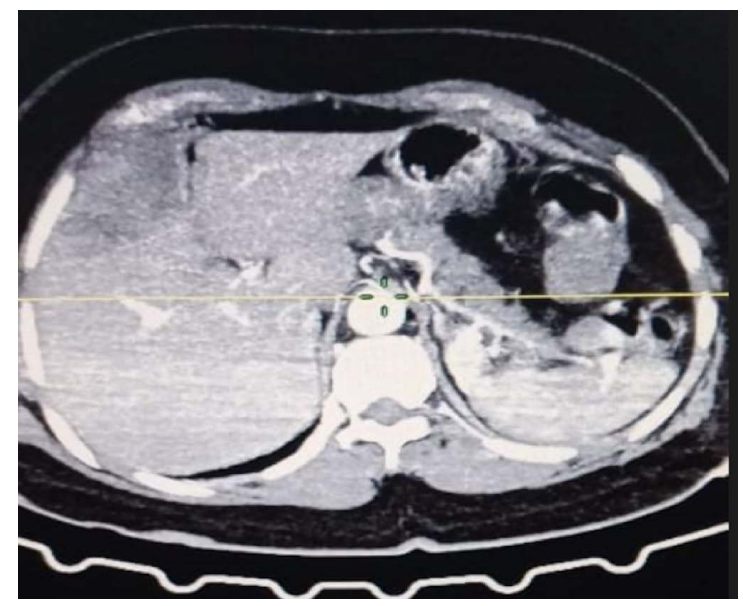

Figure 2. Angiography CT scan image showing stent migration. 


\section{Discussion}

Aorto digestive fistulas are rare but deadly causes of digestive bleeding. The primitive ones are rare (250 cases described in the literature [5] [6] with an incidence of $0.04 \%-0.07 \%$. They generally occur of novo, usually due to the erosion of a bulky aortic aneurism in the digestive tract; they can also be related to the existence of cancer or an infection, radiotherapy or traumatism. The secondary aorto digestive fistulas are more frequent, with an incidence of $0.36 \%-2 \%$ among patients who had an aortoiliac abdominal rebuilding [6] [7] and especially after a prosthetic transplant. A secondary aorto-enteric fistula is a communication between the aorta and a segment of the adjacent digestive tract, at a patient having undergone an aortic surgery as a preliminary, with or without aortic stent. It is generally the ultimate evolutionary complication of a chronic infection of aortic stent. It interests the duodenum in its third section [8] [9].

\subsection{Diagnosis}

Aorto-duodenal, colic, gastric and rectal fistulas present a more or less common semiology characterized by the following symptoms [10]:

- Digestive bleeding, present in $94 \%$ of the cases, brutal and massive, is often preceded by hemorrhagic episodes more limited and "contained" (herald bleeding), and can be explained by the formation of a clot blocking the fistula. The hematemesis is present in $78 \%$ of the cases.

- Abdominal pain, lumbar with possible irradiation towards the back is present in $48 \%$ of the cases.

- Melena is present in $46 \%$ of the cases, the blood depletion with anemia and shock was found in $33 \%$ of the cases.

- Pulsatile Mass in $17 \%$ of the cases

- Syncope in $10 \%$ of the cases.

- Infection: can appear by a prolonged and unexplained isolated fever, a delay of cicatrization of a septic wound, a large red leg and biologically with hyperleucocytosis and an increase in the rates of fibrinogen and sometimes of $\mathrm{C}$ reactive protein [10].

Upper GI endoscopy: remains a fundamental examination in all patients with an aortoiliac or aorto femoral stents with upper digestive bleeding: to look for possible erosions of the digestive wall by the stent (which is unfortunately only very rarely visualized including by the endoscopic video capsule), but especially to eliminate other causes of bleeding (particularly a peptic ulcer ("stress") or a rupture of esophageal varices). Colonoscopy may be helpful in some patients for the same reasoning [11].

Angio CT SCAN: is currently the gold standard examination but with variable sensitivity and specificity (sensitivity $40 \%$ to $90 \%$ and specificity $33 \%$ to $100 \%$ [12]). The criteria in favor of aortodigestive fistula are:

- Presence of gas images within a perish-stent collection.

- Thickening and/or retraction of the intestinal walls to the contact. 
- Presence of a false aneurism.

- Perish-stent liquid Collection.

- The extravasation of the contrast product in the intestine is almost never visualized, its absence should not exclude the aorto-enteric diagnosis of fistula.

Its puncture of a per-prosthetic collection can make it possible to confirm the infection and to specify the germ causes some [13] [14] [15] [16] [17].

Our three patients have in common the severe presentation of initial bleeding, 2 out of three patients had a medical history of Behçet disease which is one of the frequent causes of arterial aneurysms.

\subsection{Treatment}

The aneurysms of the abdominal aorta are more frequent than occlusions and constitute a major cause of mortality because of the risk of rupture [18] [19]. Their treatment associates surgery with medical care including corticosteroids and immunosuppressive therapy aiming at decreasing the recurrence of the arterial attack.

Classically, the treatment of aorto digestive fistulas is surgical, well said, laparotomy, removal of the stent, ligation of the aorta and extra anatomical bypass [19]. Even an in situ aortic replacement using allografts or grafts. Antibiotic-impregnated stents may be an alternative with lower morbidity and mortality [20]. More recently the use of minimally invasive techniques, such as the placement of stent-grafts and the removal of fistulas with glues, have been reported [20].

The goals of surgical treatment are:

- Control the bleeding

- Repair the intestinal lesion

- Parry infected tissue

- Protect the vascular sutures to limit the risk of disunity or recurrence.

- Restore arterial circulation.

As the mortality and morbidity rates of this surgery are high, various treatment options have been proposed to reduce surgical trauma and decrease the incidence of postoperative complications. However, aortodigestive fistula's surgery still has a high incidence of mortality and major complications, regardless of the techniques adopted [21] [22] [23].

\section{Conclusion}

Aorto digestive fistula is an extremely serious complication of aortic aneurysms and a rare cause of gastrointestinal bleeding. This diagnosis should be considered in any patient presenting with digestive bleeding without an identifiable cause and a fortiori if this patient is a carrier of the stent. Abdominal CT angiography is the initial examination of choice when it is suspected, allowing the diagnosis and urgent surgical indication to be made, the patient's only chance of survival. 


\section{Conflicts of Interest}

The authors declare no conflicts of interest regarding the publication of this paper.

\section{References}

[1] Lemos, D.W., Raffetto, J.D., Moore, T.C., Menzoian, O.J. (2003) Primary Aortoduodenal Fistula: Box Carryforward and Review off the Literature. Journal of Vascular Surgery, 37, 686-689. https://doi.org/10.1067/mva.2003.101

[2] Song, Y., Liu, Q., Shen, H., et al. (2008) Diagnosis and Management off Primary Aortoenteric Fistulas-Experiment Learned from Eighteen Patient. Surgery, 143, 43-50. https://doi.org/10.1016/j.surg.2007.06.036

[3] Saers, S.J.F. and Scheltinga, M.R.M. (2005) Primary Aortoenteric Fistula. British Journal of Surgery, 92, 143-152. https://doi.org/10.1016/j.surg.2007.06.036

[4] Champion, M.C., Sullivan, S.N., Adhesives, J.C., Goldbach, M. and Waltson, W.C. (1982) Aortoenteric Fistula Incidence, Recognition Presentation, and Management. Annals of Surgery, 195, 314-317. https://doi.org/10.1097/00000658-198203000-00011

[5] Dorigo, W., Pulli, R., Azas, L., Pratesi, G., Innocenti, A.A. and Pratesi, C. (2003) Early and Length-Term Results off Conventional Surgical Treatment off Secondary Aortoenteric Fistula. European Journal of Vascular and Endovascular Surgery, 26, 512-518. https://doi.org/10.1016/S1078-5884(03)00379-4

[6] Thomson, V.S., Gopinath, K.G., Joseph, E. and Joseph, G. (2009) Primary Aorto-Enteric fistula: A Rare Complication off Abdominal Aortic Aneurysm. Journal of Postgraduate Medicine, 55, 267-269. https://doi.org/10.4103/0022-3859.58930

[7] Song, Y., Liu, Q., Shen, H., Jia, X., Zhang, H. and Qiao, L. (2008) Diagnosis and Management off Primary Aortoenteric Fistulas-Experiment Learned from Eighteen Patient. Surgery, 143, 43-50. https://doi.org/10.1016/j.surg.2007.06.036

[8] Arboui, S., Jarraya, H., Mahjoub, W., Baccar, M., Kacem, C., Abdesselem, M.M. and Zaouche, A. (2008) Primary Aorto-Enteric Fistula in a 52-Year-Old Man. La Tunisie Medicale, 86, 830-832.

[9] Chenu, C., Marcheix, B., Barcelo, C. and Rousseau, H. (2009) Abdominal Aorto-Enteric Fistula after Endovascular Aortic Aneurysm to Repair: Put Carryforward and Review. European Journal of Vascular and Endovascular Surgery, 37, 401-406. https://doi.org/10.1016/j.ejvs.2008.11.037

[10] Ahn, M., Shin, B.S. and Park, S.-H. (2011) Secondary Dent Aorto-Oesophagienne with the Installation of One Stent Oesophagien: Treatment in Urgency by Cyanoacrylate and Stentgraft. Annals of Vascular Surgery, 24, 604.

[11] Akbas, T., Duman, D., Tahan, V., Barghi, I. and Tozun, N. (2009) Aorto-Enteric Fistula: Dilemma for the Endoscopist Ace Has Rare Cause off Gastrointestinal Bleeding Has. Acta Chirurgica Belgica, 109, 541-543. https://doi.org/10.1080/00015458.2009.11680481

[12] Considering, Q.D., Menias, C.O., Bhalla, S., Peterson, C., Wang, L. and Balfe, D.M. (2009) Aortoenteric Fistulas: CT Features and Potential Mimics. Radiographics, 29,197-209. https://doi.org/10.1148/rg.291075185

[13] Mathias, J., Mathias, E., Jausset, F., Oliver, A., Sellal, C., Laurent, V. and Regent, D. (2012) Aorto-Enteric Fistulas: A Physiopathological Approach and Computed Tomography Diagnosis. Diagnostic and Interventional Imaging, 93, 840-851. https://doi.org/10.1016/j.diii.2012.07.003 
[14] Notkovich, H. (1956) Variations off the Testicular and Ovarian Arteries in Relation to the Pedicle. Surgery, Gynecology \& Obstetrics, 103, 487-495.

[15] Juskiewenski, S. and Vaysse, P. (1978) Arterial Vascularization off the Test and Surgery for Undescended Testicles (Testicular Ectopia). Anatomia Clinica, 1, 127-134.

[16] Matrane, A., Mariaule, E., Martin, P. and Bergmann, P. (2009) Lower Gastrointestinal Bleeding: Contribution off Labeled Erythrocytes Scintigraphy. Revue medicale de Bruxelles, 30, 55-58.

[17] Gerald, P.S., Gerczuk, P.Z., Idupuganti, R., Patnana, M. (2007) Massive Gastrointestinal Bleeding Due to Year Aorto-Enteric Fistula Seen by Technetium-99m-Labeled Red Blood Concealment Scintigraphy. Clinical Nuclear Medicine, 32, 551-552. https://doi.org/10.1097/RLU.0b013e31806541bf

[18] Taberkant, M., Chtata, H., Lekehal, B., Alaoui, M. and Sefiani, Y. (2003) Boughroum Have and Al Anévrisme of the Abdominal Aorta During the Disease of Behçet in Connection with Four Cases. J Badly Vasc, 28, 265-268.

[19] Barleben, A.R., Baig, M.S., Kubaska, S.M., Fujitani, R.M., Gordon, I.A. and Lane, J.S. (2007) Endovascular Repair of an Actively Hemorrhaging Aortoduodenal Fistula. Annals Vascular Surgery, 21, 629-632. https://doi.org/10.1016/j.avsg.2007.01.011

[20] Lirici, M.M., Tierno, S.M., Giudice, R., Coscarella, C., Graziani, M.G. and Pogany, G. (2020) Secondary Aortoenteric Fistula Successfully Treated with Staged Endovascular Repair and Duodenal Resection without Graft Removal. Minimally Invasive Therapy \& Allied Technologies, 29, 114-119. https://doi.org/10.1080/13645706.2019.1581623

[21] Kahn, P.C. (1967) Selective Angiography off the Inferior Phrenic Arteries. Radiology, 88, 1-8. https://doi.org/10.1148/88.1.1

[22] Lippert, H. and Pabst, R. (1985) Arterial Variations in Man: Classification and Frequency. JF Bergmann, München.

[23] Vandamme, J.P., Kindness, J., van der Schueren, G. (1969) A Revaluation off Hepatic and Cystic Arteries. Aberrant The Importance off the Hepatic Branches. Acta Anatomica, 73, 192-209. https://doi.org/10.1159/000143296 